\title{
Correction to: Factors Predicting Provisioning of Macaques by Humans at Tourist Sites
}

\author{
Asmita Sengupta ${ }^{1,2} \cdot$ Sindhu Radhakrishna ${ }^{2}$ \\ Published online: 24 August 2020 \\ (C) Springer Science+Business Media, LLC, part of Springer Nature 2020
}

\section{Correction to: International Journal of Primatology (2020) 41:471-485 https://doi.org/10.1007/s10764-020-00148-5}

The original version of this article unfortunately contained a mistake in the Acknowledgements section. The modified version is presented below:

Acknowledgements The authors wish to thank the Goa and Himachal Pradesh State Forest Departments for their support. Rupesh Gawde assisted with field work and Shaurabh Anand helped with maps. A part of this work was presented at the 27th International Primatological Society Congress held in Nairobi, Kenya August 19-25, 2018. The authors wish to thank the organizers of the symposium where this work was presented for their kind invitation. This work was supported by the Science and Engineering Research Board, Department of Science and Technology, Government of India (Grant No. SERB/F/I0032/2016-17) awarded to SR. AS is supported by the DST-INSPIRE Faculty Fellowship (DST/INSPIRE/04/2017/000124) awarded by the Department of Science and Technology, Government of India. The authors also thank Dr. Joanna M. Setchell and the two anonymous reviewers for their extremely helpful comments that helped improve the manuscript immensely.

The online version of the original article can be found at https://doi.org/10.1007/s10764-020-00148-5

\section{Asmita Sengupta}

asmita.sengupta@gmail.com

1 Ashoka Trust for Research in Ecology and the Environment, Shriramapura, Jakkur, Bangalore, Karnataka, India

2 National Institute of Advanced Studies, Indian Institute of Science Campus, Bangalore, India 